\title{
Nacionalismo e ambivalência em $O$ sertanejo, de José de Alencar
}

\author{
Nationalism and ambivalence in $O$ sertanejo \\ by José de Alencar
}

Déborah Scheidt ${ }^{*}$

\begin{abstract}
Resumo: O sertanejo é emblemático para o nacionalismo romântico brasileiro na medida em que declaradamente pretende celebrar a terra e o homem brasileiros representados pelo sertão cearense e pelo herói sertanejo Arnaldo Louredo. Inicialmente procuramos demonstrar como a manipulação do foco narrativo e o emprego repetido do pronome possessivo na primeira pessoa do plural são utilizados para criar a percepção de nação, a que se refere Benedict Anderson. A seguir avaliamos a problemática da pertença em colônias de povoamento para detectarmos ambivalências na caracterização, tanto do protagonista como do proprietário rural e capitão-mor de ordenanças Pires Campelo, fazendo uso das teorias de Homi Bhabha sobre o assunto. A conclusão a que se chega é a de que, apesar da sua aparente simplicidade, a obra acaba por deixar transparecer, na própria tentativa de encobri-las, as complexidades das origens sociais brasileiras, irremediavelmente afetadas pela colonização europeia.

Palavras-chave: Nacionalismo. Ambivalência. O sertanejo. José de Alencar.

Abstract: José de Alencar's novel O sertanejo represents the Brazilian romantic nationalistic agenda inasmuch as it openly proposes to celebrate a feature of Brazilian nature known as the "sertão" (outback) of the state of Ceará, as well as the "typical" man who inhabits it represented by the novel's hero, Arnaldo Louredo. In the first part of this essay it is demonstrated how the authorial manipulation of the narrative focus and the repeated use of first person plural possessive pronouns are employed to create the perception of nation as Benedict Anderson terms it. Next, issues related to the complex matter of land possession and alienation in colonies such as Brazil are discussed to demonstrate the ambivalence in the characterization of both the protagonist and the novel's authoritarian landowner, Captain Pires Campelo using Homi Bhabha's theories. It is concluded that despite its apparent simplicity and even in its attempt to cover them up, the novel reveals the complex social origins of Brazil irremediably affected by European colonization.
\end{abstract}

Keywords: Nationalism. Ambivalence. O sertanejo. José de Alencar.

\footnotetext{
* Doutoranda.Universidade Federal do Paraná, UFPR. Professora Assistente do Departamento de Línguas Estrangeiras Modernas. Universidade Estadual de Ponta Grossa, UEPG. E-mail: deborahscheid@, yahoo.com.br.
} 
Apesar de o título O sertanejo ser bastante conhecido - quem não se lembra de tê-lo visto, ou até mesmo memorizado, sob a classificação "romances regionalistas de José de Alencar"? -, poucos brasileiros leram esse que seria um "romance menos expressivo" (ALENCAR, 2004, p. 3) no conjunto da obra de Alencar, sobretudo quando comparado a O guarani e Senhora (este último publicado no mesmo ano, 1875). Tampouco os olhares dos críticos têm se voltado com muita frequência ou com maior profundidade para o romance, segundo Eduardo Vieira Martins (1997, p. 16), autor de uma dissertação de mestrado sobre a obra.

Portanto, raros leitores têm seguido a cavalgada do herói sertanejo Arnaldo Louredo no Ceará colonial de 1764, desbravando o "inextricável labirinto de troncos e ramos tecidos por mil atilhos de cipós, mais fortes de que uma corda de cânhamo, e crivado de espinhos" (ALENCAR, 2004, p. 147), em perseguição ao boi Dourado, um exemplar quase mítico e há sete anos invencível de "gado barbatão", ou gado que se afastara dos rebanhos domesticados, tornando-se selvagem.

No capítulo V da segunda parte do romance, intitulado "A Carreira", as habilidades de Arnaldo às cegas, no mato fechado, são comparadas, com vantagem, às dos melhores cavaleiros tanto do velho quanto do novo mundo (árabes, citas, índios guaicurus e gaúchos), cujas proezas se resumem a manejar "seus corcéis no descampado" (idem, p. 147). Há um momento em que o boi fica preso em um emaranhado de cipós; Arnaldo espera que se desvencilhe para então retomar a carreira, já que "tratava o Dourado com a gentileza que os cavalheiros usavam outrora no combate". (p. 148) Logo, porém, o sertanejo o alcança novamente: "Emparelhou [...] seu cavalo com o boi, e passando o braço pelo pescoço deste, continuaram assim a corrida por algum tempo ainda. Afinal o boi parou; reconheceu que fugia debalde; já tinha na cabeça o laço que o vaqueiro the passara rapidamente.” (p. 148) Aquele boi representa para Arnaldo a fama de "primeiro campeador" (p. 149), a humilhação de seu arrogante rival Marcos Fragoso e a exultação de sua amada, D. Flor. Ainda assim Arnaldo, fitando seu olhar choroso, decide poupá-lo, pois afinal, como poderia um "touro livre e brioso" ser reduzido "a um boi de curral, ou talvez a um cangueiro"? (p. 149) Contenta-se com marcá-lo a ferro com uma pequena flor, "o emblema da mulher a quem idolatrava" (p. 150), despedindo-se dele com essa fala: 
- Fique descansado, camarada, que não o envergonharei levando-o à ponta de laço para mostrá-lo a toda aquela gente! Não; ninguém há de rir-se da sua desgraça. Você é um boi valente e destemido; vou dar-lhe a liberdade. Quero que viva muitos anos, senhor de si, zombando de todos os vaqueiros do mundo, para um dia, quando morrer de velhice, contar que só temeu a um homem, e esse foi Arnaldo Louredo. (p. 150)

Esse pequeno resumo revela muito do que se espera de um romance romântico brasileiro: enaltecimento das habilidades físicas do brasileiro comum, enobrecimento de seu caráter, representação poetizada do meio natural, identificação do herói com a natureza, descrição de costumes locais e comparação destes com os do velho mundo, e criação de um passado comparável ao da Europa medieval. Fica claro que Alencar trata sua atividade literária, como observa Candido (2006, p. 28) "como parte do esforço de construção de um país livre, em cumprimento a um programa, bem cedo estabelecido, que visava à diferenciação e particularização dos temas e modos de exprimi-los."

Com efeito, para Antoine Compagnon (2003, p. 32-33), o "sentido moderno da literatura é inseparável do romantismo, isto é, da relatividade histórica e geográfica do bom gosto, em oposição à doutrina clássica da eternidade e da universalidade do cânone estético." No romantismo "a literatura é concebida [...] em suas relações com a nação e com sua história. A literatura, ou melhor, as literaturas são, antes de tudo, nacionais." Assim como em Compagnon, a vinculação das literaturas do final do século XVIII e do século XIX aos nacionalismos literários é um lugar comum na crítica e história literária ocidental.

O cientista político Benedict Anderson, porém, vai além da constatação do surgimento das literaturas nacionalistas como decorrência dos movimentos políticos, invertendo a equação: ele sugere que a própria ideia de "nação" advém da expansão do que denomina "capitalismo secular tipográfico": a comercialização em larga escala de romances e jornais escritos nas línguas vernáculas de cada grupo, em contraposição às literaturas em língua sacra e de acesso restrito que predominavam até então.

Sua teoria sobre a origem da "nation-ness" - neologismo aproximadamente traduzível como "condição nacional" - é a de que, no decorrer do século XIX, o fato de milhares (ou milhões) de pessoas desconhecidas entre si, mas ao mesmo tempo conscientes da existência coletiva uns dos outros, lerem exemplares idênticos de um romance ou as mesmas notícias em um jornal, foi capaz de gerar uma sensação de grupo (já que todas faziam parte de 
um mesmo campo linguístico) bastante intensa, mas limitada, já que apenas essas pessoas podiam pertencer ao grupo. Para Anderson (2009, p. 80) “[e]sses companheiros de leitura, aos quais estavam ligados através da letra impressa, constituíram, na sua invisibilidade visível, secular e particular, o embrião da comunidade nacionalmente imaginada."

Antonio Candido (1967, p. 91-95) examina esse momento da história literária brasileira no final do século XVIII e início do XIX, quando o papel social do escritor finalmente se delineia como atividade diferenciada no Brasil e a primazia do modelo português da era colonial dá lugar a um enérgico nacionalismo militante, manifesto em gêneros literários utilitários de ordem religiosa, jornalística e cívica, dirigidos a um público sedento por encontrar na literatura ecos para seus anseios emancipatórios e para sua busca por autoestima. O romance nasce no Brasil impregnado dessa perspectiva ideológica, e o resultado é o que Candido considera possivelmente o mais significativo episódio de influência literária sobre o público já ocorrido no Brasil.

Mas, na prática, como pode a literatura reforçar, como pensa a maioria dos críticos, ou até mesmo gerar a percepção de nação? Anderson (2009, p. 58) demonstra que o tipo de foco narrativo adotado por um romancista pode ser um dos elementos contribuintes para a criação de uma "comunidade imaginada". Em sua análise de um excerto de romance filipino, ele percebe que a alternância do 'tempo 'interno' do romance para o tempo 'externo' da vida cotidiana do leitor [...] fornece uma confirmação hipnótica da solidez de uma única comunidade, abrangendo personagens, autor e leitores, e avançando no tempo do calendário", isto é, aludindo a uma situação ou cenário familiar a esses três grupos.

Fenômeno semelhante, porém algo mais complexo, ocorre em várias passagens de $\mathrm{O}$ sertanejo. Atendo-nos ao primeiro capítulo do romance, já é possível perceber, por exemplo, uma oscilação entre descrição e narração. A descrição alude ao "tempo do calendário", a uma paisagem que, se não pertencente ao cotidiano da maioria dos leitores (algo inviável, dada a extensão quase continental do território), é claramente identificada como brasileira pelo próprio narrador:

Esta imensa campina, que se dilata por horizontes infindos, é o sertão de minha terra natal.

Aí campeia o destemido vaqueiro cearense, que à unha de cavalo acossa o touro indômito no cerrado mais espesso, e o derriba pela cauda com admirável destreza. (ALENCAR, 2004, p. 13). 
Sem que a câmera autoral se desloque da cena, temos, alguns parágrafos abaixo, a narração de um fato ficcional passado há quase um século do tempo da narrativa, correspondendo ao "tempo interno"do romance: "Assim fizera o dono do comboio que no dia 10 de dezembro de 1764 seguia pelas margens do Sitiá buscando as faldas da Serra de Santa Maria, no sertão de Quixeramobim." (ALENCAR, 2004, p. 13).

Concomitantemente às combinações de tempo presente/passado e descrição histórica/ficcional, vemos também uma articulação entre primeira, segunda e terceira pessoas do singular e primeira pessoa do plural. O uso do pronome possessivo na primeira pessoa do plural é especialmente relevante no discurso nacionalista:

Atualmente viaja-se pelo nosso interior em hábitos caseiros; não era assim naquele bom tempo em que um capitão-mor julgaria derrogar da sua gravidade e importância, se fossem vistos na estrada, ele e a esposa, sem o decoro que reclamava sua jerarquia. (ALENCAR, 2004, p. 14, grifo meu).

Como novamente nos lembra Anderson (2009, p. 64), a presença desse possessivo em particular pode sugerir que o elemento geográfico referido pertence "ao coletivo de leitores" brasileiros e, portanto, tacitamente, a "uma comunidade imaginada [brasileira] em embrião." Com efeito, em diversas outras passagens ao longo do romance, o uso da primeira pessoa do plural reforça esse elo de identificação nacionalista entre autor, personagens e leitores em expressões como "nossos avoengos" (p. 29), "nossos antepassados" (p. 90), "nossos tempos" (p. 91), "nossos sertões" (p. 103), "nossos costumes sertanejos" (p. 119).

$\mathrm{Na}$ maioria dos casos onde aparece esse pronome específico em $\mathbf{O}$ sertanejo, as passagens são puramente descritivas, em parágrafos especialmente destinados a esclarecer aspectos históricos ou geográficos externos à trama, criando uma sensação compartilhada de brasilidade entre escritor e público. No seguinte trecho, porém, a estratégica retórica do uso do possessivo assume uma força especial ao aliar, em uma única sentença, referentes relacionados aos personagens ficcionais a referentes histórico-geográficos (ou o tempo interno ao externo, na linguagem de Anderson):

Também D. Genoveva, se não fosse o recato de seu sexo, de que o marido não a dispensava, ainda mais em presença de estranhos, tomaria 
parte na montearia, para que se julgava com ânimo e disposição. Era ela destemida cavaleira; e decerto desempenhar-se-ia melhor da empresa do que o Ourém e o Correia, moradores da cidade, e não afeitos a esses exercícios dos nossos campos. (ALENCAR, 2004, p. 138, grifo meu).

Esses exemplos evidenciam o esforço de uma conscientização identitária coletiva que acaba se materializando não somente por meio da temática escolhida, mas também pela adoção de um foco narrativo em que o narrador pretende dominar todos os aspectos da narrativa, acabando, eventualmente, por imiscuir-se na voz dos personagens. Assim, verificamos a estratégica retórica nacionalista de Alencar manifestando-se além da temática e da linguagem (motes usuais da crítica alencariana) e atingindo a estrutura do romance.

Entretanto, como observa Candido (1967, p. 98), ao mesmo tempo em que o romance romântico brasileiro pretende ser nacionalista, libertário e divisor de águas, ele não pode prescindir do aval oficial, já que tanto as associações literárias que proliferavam na época, quanto a maior parte dos literatos, faziam parte do aparato governamental, eram patrocinados ou, de outro modo, favorecidos, pelo Império. Na verdade, como observa Anderson (2009, p. 89), em meio à "revolução cultural" dos republicanismos nas Américas, o Brasil era a única nação que reproduziu no novo mundo o regime monárquico-dinástico europeu.

Essa tensão, dentre tantas outras, aponta para a problemática dos nacionalismos literários. Nesse campo de estudos são recorrentes termos como "ambiguidade", "alienação", "alteridade", "apropriação", na tentativa, nem sempre bem-sucedida, como observam Chris Tiffin e Alan Lawson (1994, p. 6), de desbancar, ou pelo menos tentar evitar, os binarismos tradicionalmente vistos como fundadores do pensamento ocidental. Os mesmos autores citam como exemplo dessa complexidade os casos de países que foram "colônias de povoadores", como o Brasil, em que a dicotomia entre "self" e "outro" se faz sentir de maneira especialmente problemática. Thomas Bonnici formula essa questão nos seguintes termos:

\footnotetext{
${ }^{1}$ Do inglês settler colonies, como a América do Sul, a América do Norte e a Oceania, onde de acordo com Bonnici (2009, p. 263) "a terra foi ocupada por colonos europeus que conquistaram, mataram ou deslocaram as populações indígenas. Uma modalidade de civilização europeia foi transplantada no vazio construído e os descendentes de europeus, mesmo após a independência política, mantiveram o idioma não indígena."
} 
Nas colônias de povoadores, o brasileiro, o canadense, o australiano, todos brancos, consideram o índio, o inuit, o aborígine, como alheio/ outro. Se o índio é o alheio, como pode ser indígena? Logo, o brasileiro branco deve ser o outro e o alheio. Mas como o brasileiro pode ser alheio em sua própria terra? (BONNICI, 2005, p. 13).

Assim como essa controvérsia sobre a "pertença" do brasileiro, as narrativas de países afetados pelo colonialismo europeu estão repletas de ambivalências. O termo "ambivalência" foi cunhado no início do século XX para referir-se, em psicanálise, a sentimentos contraditórios com relação a um mesmo estímulo, mas tem se mostrado especialmente útil nas tentativas de se descrever a complexidade de sentimentos envolvidos na relação entre colonizador e colonizado. De acordo com Bill Ashcroft et al. o relacionamento pós-colonial:

[...] é ambivalente porque o sujeito colonizado nunca se encontra em simples e perfeita oposição ao colonizador. Ao invés de presumir que alguns sujeitos colonizados são "coniventes" enquanto que outros são "resistentes", a ambivalência sugere que a conivência e a resistência coexistem numa relação volúvel num mesmo sujeito colonial. A ambivalência também caracteriza a maneira pela qual o discurso colonial se relaciona com o sujeito colonizado, já que esse discurso pode ser ao mesmo tempo abusivo e benevolente, ou representar-se como benevolente. (ASHCROFT, 2000, p. 12, minha tradução).

Vários críticos têm utilizado o conceito de ambivalência, mesmo quando não fazem propriamente uso do termo. Dentre os brasileiros é o caso, por exemplo, de Silviano Santiago (1978, p. 28), que na década de 1970 adotou a expressão "entre-lugar" para tratar das questões de "submissão ao código" e "transgressão" do discurso latino-americano em relação aos padrões europeus, e de Antonio Candido, que se refere à "dupla fidelidade" (2006, p. 436) dos autores românticos brasileiros, "atentos por um lado à realidade local, por outro à moda francesa e portuguesa."

Mas é o teórico do pó. s-colonialismo, Homi Bhabha, quem tem divulgado amplamente o termoEm sua introdução à coletânea de ensaios Nation and narration $(1995$, p. 2) Bhabha, emprestando a metáfora de Tom Nairn, considera a nação como uma versão moderna do deus Janus (o deus romano das portas, portões e entradas e saídas em geral: daí as suas duas faces). Para Bhabha e Nairn, mais do que um artifício retórico, a própria natureza da ideia de nação é ambivalente e antíteses como progressão/regressão, racionalidade/ 
irracionalidade política, já vêm inscritas em seu “código genético", em decorrência, segundo os autores, das desigualdades promovidas pelo capitalismo. As narrativas que tentam representar a condição nacional (a "nation-ess" de Anderson), portanto, também estão irremediavelmente fadadas a serem ambivalentes.

Uma das ambivalências da obra alencariana que está relacionada ao projeto nacionalista romântico diz respeito à verossimilhança nos romances. Essa discussão não é nova, tendo sido iniciada por intelectuais contemporâneos a José de Alencar, notadamente Franklin Távora e Joaquim Nabuco, com os quais o escritor se envolveu em acirradas polêmicas. Nabuco (apud Martins, 2005, p. 190), criticando O guarani, já se refere à problemática da pertença, acusando Alencar de criar uma "falsa" literatura tupi e apontando uma das ambivalências inerentes ao projeto nacionalista, ao questionar a "pretensão" de Alencar em converter os costumes indígenas em brasileiros: "é impossível [...] querer-se fazer dos selvagens a raça, de cuja civilização a nossa literatura deve ser o monumento. Nós somos brasileiros, não somos guaranis; a língua que falamos, é ainda a portuguesa." Além disso, ecoando as críticas à suposta "literatura de gabinete" de Alencar feitas anteriormente por Távora, Nabuco questiona a propriedade da representação tanto dos personagens indígenas quanto da natureza brasileira.

Em suas réplicas, Alencar defende sua perspectiva de verossimilhança, que Eduardo Vieira Martins (2005, p. 194-5) traduz em termos barthesianos "a partir de duas ordens distintas de argumentos: na primeira o verossímil é concebido de perspectiva referencial, na segunda como efeito discursivo interno ao texto." Um dos episódios questionados por Nabuco, em que Peri se envenena com curare numa tentativa de matar os canibais que se alimentassem dele, é defendido tanto por sua acuidade científica (em nota de rodapé ao romance, Alencar havia citado uma autoridade sobre a ação química do curare), quanto no tocante ao comportamento do personagem e seu direito de sacrificar-se, em consonância com o "relevo de seu caráter" e "o assomo de sua paixão". Em outras argumentações de semelhante teor, Alencar justifica suas escolhas adotando a mesma postura de evocar, quando possível, argumentos externos à literatura e a "autoridade científica" e, falhando isso, a liberdade do escritor em criar uma realidade coerente do ponto de vista interno.

Martins (2005, p. 196) sustenta que, para o próprio Alencar, essa ambivalência não se constitui um defeito, mas uma característica própria 
da complexidade do gênero romance. De qualquer modo, $\mathbf{O}$ sertanejo, que muitos críticos vêem como uma reescrita de O guarani (MARTINS, 1997, p. 16-19) demonstra que Alencar, ao mesmo tempo que mantém sua técnica narrativa favorita para romances de temática rural: a alternância entre ação puramente ficcional e elementos extraliterários, aperfeiçoa a arte de incorporar as explicações lógicas para o comportamento do protagonista ao corpo do texto, prescindindo do uso extensivo das notas de rodapé que caracterizam O guarani. Assim, após a cena em que Arnaldo passa a noite tranquilamente no topo de uma árvore com uma onça a seus pés, segue-se o comentário de que os sertanejos viajantes realmente têm o hábito de estender suas redes nos cumes das árvores para proteger-se desses felinos, cujo peso os impede de tentar alcançar os galhos mais finos. (ALENCAR, 2004, p. 37-40)

Do mesmo modo que esse episódio sertanejo, com seu fundo de verdade, é incorporado à trama - e de uma maneira bem mais espontânea do que a forma de notas de rodapé que predomina em O guarani - Alencar incorpora diversos outros elementos da história, geografia, botânica e da cultura sertaneja cearense no romance: crônicas da província, descrições de festivais populares, superstições e crendices, ditos e anedotas, medicina popular, descrição da arte local, exemplos de cantigas folclóricas e descrição de cenas da vida privada.

Candido (2006, p. 28) também comenta essa ambivalência e o modo como os escritores pós Independência tentaram articular a necessidade de transcendência do real, que é própria da literatura (não só a romântica), e o esforço de construir uma "literatura empenhada", que "acarretava a obrigação tácita de descrever a realidade imediata":

Este nacionalismo infuso contribuiu para certa renúncia à imaginação ou certa incapacidade de aplicá-la devidamente à representação do real, resolvendo-se por vezes na coexistência de realismo, fantasia, documento e devaneio, na obra de um mesmo autor, como José de Alencar. Por outro lado favoreceu a expressão de um conteúdo humano, bem significativo, dos estados de espírito duma sociedade que se estruturava em bases modernas. (CANDIDO, 2006, p. 28-29).

Tanto o critério da verossimilhança quanto o da originalidade têm sido invocados por alguns críticos que, ao colocarem lado a lado $\mathbf{O}$ guarani e $\mathbf{O}$ sertanejo, pendem a balança a favor do primeiro. Araripe Júnior, em 1882, considera $O$ sertanejo como "sombra pálida do Guarani” (apud MARTINS, 1997, p. 16), e mais recentemente, na década de 1970, Wilson Martins vê $O$ 
sertanejo como uma reedição das "fórmulas alencarianas mais fáceis". (apud MARTINS, 1997, p. 18) No entanto, como vimos acima, tanto em termos estruturais como em termos desse "conteúdo humano" de que nos fala Candido, O sertanejo não parece estar em posição inferior. Como conclui Candido (2006, p. 436), os bons romancistas regionalistas do romantismo "não foram irreais na descrição da realidade social, mas apenas nas situações narrativas."

Todas as situações narrativas têm como centro a figura de Arnaldo. Ele sozinho desempenha diversos atos heroicos (tais como o que vimos na abertura deste trabalho), desafia perigos, vence brigas e torneios, e chega, mais de uma vez, a incorrer na ira do seu senhor, o capitão-mor Pires Campelo, ao desobedecê-lo, algo impensável para todos os outros personagens sujeitos à rígida hierarquia de seu patriarcado. Visto por todos como um agregado, Arnaldo recusa-se a ter qualquer vínculo empregatício, mesmo o cobiçado cargo de primeiro vaqueiro. Seu principal valor é o livre arbítrio, que apregoa em várias passagens do romance. Desde criança demonstra uma "altivez estranha em sua posição", parecendo-se com um "príncipe maltrapilho" (ALENCAR, 2004, p. 182) e mostrando "repugnância para todo o serviço obrigatório, feito por ordem e conta de outro." (p. 183) Essa atitude, porém, convive, no mesmo personagem, com uma fidelidade a toda prova, que se manifesta na orgulhosa resposta que o protagonista dá ao capitão-mor, ao ser repreendido por desobediência: "se não presto para camarada ou vaqueiro, quando se tratar de o defender e acatar, a si e aos que lhe são caros, pode contar que não tem servidor mais pronto, nem mais devoto. Minha vida lhe pertence, é dispor dela como lhe aprouver." (p. 76)

Essa fala de Arnaldo comprova o que Bosi observa no indianismo de Alencar, mas que também pode ser verificado no sertanejo, já que Arnaldo é o "sósia rústico de Peri" (BOSI, 2005, p. 178):

A concepção que Alencar tem do processo colonizador impede que os valores atribuídos romanticamente ao nosso índio - o heroísmo, a beleza, a naturalidade - brilhem em si e para si; eles se constelam em torno de um ímã, o conquistador, dotado de uma poder infuso de atraí-los e incorporá-los. (idem, p.180-1)

A lealdade incondicional de Arnaldo à família Campelo, tendo-lhes salvo a vida, a honra e a fortuna, rende-lhe somente a reiteração de sua submissão e, finalmente, no último capítulo, a perda de sua identidade:

- E para si, Arnaldo, que deseja? insistiu Campelo.

- Que o senhor capitão-mor me deixe beijar sua mão; basta-me isso. 
- Tu és homem, e de hoje em diante quero que te chames Arnaldo Louredo Campelo. (ALENCAR, 2003, p. 246)

Resta a Arnaldo amar em segredo. A consciência de sua inferioridade social - desde o início da narrativa fica claro que Arnaldo conhece perfeitamente bem sua condição social e não nutre expectativas em ter sua paixão correspondida -, e uma crescente cólera secreta se manifestam no ato egoísta e bem pouco heroico de sabotar todas as relações amorosas de D. Flor e até atingir seu noivo com uma flecha, no momento da cerimônia de casamento. Diferentemente de $O$ Guarani, em que, talvez devido à maior distância histórica, como observa Candido (2006, p. 435), era mais fácil dar asas à utopia retrospectiva, em $\mathbf{O}$ sertanejo, onde "a língua e os costumes eram próximos dos da cidade", o hibridismo social não pode se concretizar. Arnaldo representa a materialização ficcional do sujeito colonial ambivalente, "ao mesmo tempo resistente e conivente" (Ashcroft et al, 2000, p. 12) como propõem Ashcroft et al, suscitando também a questão da pertença nas colônias de povoamento, de que nos fala Bonnici.

Mas, se por um lado Alencar não consegue verdadeiramente celebrar as qualidades de agência humana e resistência do brasileiro comum, mesmo que este seja o protagonista de sua trama e representante da brasilidade que pretende apregoar, sua postura perante o que considera a verdadeira "fidalguia sertaneja" é bem diferente. É significativo que Pires Campelo tenha o título de "capitão-mor de ordenanças", que é outorgado pela coroa e combina autoridade militar, administrativa e latifundiária, sugerindo uma herança do regime de capitanias hereditárias e prenunciando o sistema de coronelismo. No seguinte excerto fica claro que a intenção do capitão-mor é ser "mais fidalgo do que os fidalgos da corte":

Formalista severo, adicto às regras e cerimônias, que se esmerava em observar escrupulosamente, imbuído de uma gravidade que tinha por essencial ao decoro de uma pessoa de sua categoria e posição, sujeitava todos os afetos como todos os interesses a essa rigorosa disciplina das maneiras.

Não era, porém, esse modo do Campelo a afetação ridícula de meneios em que se requinta a fatuidade; e sim uma temperança de gesto e de palavra, que se comediam pelo receio de descaírem em vulgaridade.

Nascia tal resguardo do nobre estímulo de manter o estado que lhe havia criado a fortuna. Campelo provinha de sangue limpo, mas plebeu; e 
almejando um pergaminho de nobreza, que enfim alcançara, ele queria merecê-lo por seus dotes e ser primeiro fidalgo na pessoa, do que no brasão. (ALENCAR, 2004, p. 32)

Essa profunda consciência da necessidade de manutenção de status social se aproxima da estratégia de "mimicry" ou o mimetismo que o colonizador ao mesmo tempo encoraja e teme no colonizado, descrita por Bhabha (1987, p. 318) e, em outros termos, por Anderson (2009, p. 138). Na complexa teia de relações sociais nas colônias de povoamento, como vimos acima, o capitão-mor ocuparia, ao mesmo tempo, o papel de colonizador perante seus subordinados coloniais e de colonizado perante a fidalguia "legitimamente" portuguesa. Daí a sua insegurança e necessidade de autoafirmar-se com atitudes draconianas, como comprova o excerto acima.

Mas é importante perceber-se como é a própria voz narrativa, e não a voz do personagem, quem faz a apologia dos direitos da aristocracia às terras e ao poder colonial, ao justificar o autoritarismo do capitão-mor. Em todos os episódios em que Campelo comete algum tipo de crueldade ou violência, como quando pretende torturar o chefe indígena Anhamum, ou quando se prepara para atirar no cavalo do sequestrador em que também julga estar sua filha, já que prefere vê-la morta a desonrada, esse mecanismo entra em ação: além de não transparecer nenhum tipo de indignação por parte dos outros personagens, a voz narrativa, ora se cala, ora justifica a decisão em termos conciliatórios.

A consciência de classe de Pires Campelo é evidenciada também pela ostentação do "luxo régio" de seu estilo de vida: "Havia fazendeiro, e o capitão-mor Campelo era um deles, que não comia senão em baixela de ouro, e que trazia na libré de seus criados e escravos, bem como nos jaezes de seus cavalos, brocados, veludos e telas de maior custo e primor do que usavam nos paços reais de Lisboa os fidalgos lusitanos." Era desse modo que os ricos fazendeiros procuravam suprimir "em torno de si o deserto que os cercava." (ALENCAR, 2004, p. 29)

Vários são os episódios que demonstram a admirável capacidade de Alencar em realizar esse ajuste criativo de elementos da suntuosidade aristocrática europeia à natureza brasileira. A cena inicial do romance, mostrando a passagem do grupo de viajantes pelo sertão, é exemplo disso. Significativamente, a descrição obedece a uma ordem hierárquica ${ }^{2}$ : inicia-se

\footnotetext{
${ }^{2}$ Martins (1997, p. 67-72) faz uma análise bastante detalhada da hierarquização nesse trecho do romance.
} 
com os peões e carregadores, passando pelos serviçais, seguranças e capataz, até centrar-se na família Campelo; mais adiante saberemos que Arnaldo, incógnito, viaja paralelamente à caravana, revelando tacitamente o seu não-lugar nessa hierarquia, ou a recusa em fazer parte desse sistema social. Os detalhes do aparato simbólico que pressupõem a tomada de posse da terra pela elite de origem europeia - a extensão do comboio, o luxo e a pompa dos uniformes, as ferramentas utilizadas para abrir caminho, as várias armas dos empregados que realizam a segurança da família, o porte do capitão e de sua esposa - formam um interessante contraste com a paisagem do sertão, duramente castigado pela seca, a "vasta planura que se estende a perder de vista", onde "se erriçam os troncos ermos e nus com os esgalhos rijos e encarquilhados, que figuram o vasto ossuário da antiga floresta." (ALENCAR, 2004, p. 15)

O esforço de Alencar, como vimos acima, é o de retratar - de um modo que hoje poderíamos chamar de cinematográfico - a chamada "zona de contato" entre culturas e espaços geográficos antagônicos, ignorando ou suavizando as conjunturas de "coerção, desigualdade radical e conflito inexequível" (PRATT, 1992, p. 6, minha tradução) que normalmente ocorrem nesses espaços. Anderson (2009, p. 278) chama isso de "as amnésias típicas" dos nacionalismos, caracterizadas por "esquecimentos, em circunstâncias históricas específicas". Das tentativas de apagamento dos conflitos nascem as representações de "unidade" da nação ou, como prefere Bhabha (1995, p. 1), a "unidade impossível da nação como força simbólica".

Assim, diferentemente da frivolidade ou do mero entretenimento que o senso comum costuma esperar do romance romântico em geral, $\mathbf{O}$ sertanejo evoca, mesmo que tacitamente, e na própria tentativa de encobri-las, as complexidades das origens sociais brasileiras, irremediavelmente afetadas tanto pela violência da colonização quanto pelas relações entre as classes sociais. A comunidade imaginada por Alencar pretende ser aquela dotada de uma natureza variada e exuberante, e da força e a coragem de um povo jovem, mas que já pode exibir ricas tradições culturais. No entanto, esse lado ensolarado da obra não consegue ocultar outro, bem mais sombrio e que constantemente vem à tona. Da tentativa do autor de "apagar o deserto", ou conciliar fantasia e realidade, o olhar europeu e o olhar autóctone, e principalmente em valorizar, simultaneamente, a liberdade do brasileiro comum e o poder patriarcal e aristocrático, surge uma face do romance extremamente perturbadora, peculiar e difícil, que merece ser olhada com mais cuidado. 


\section{Referências}

ALENCAR, José. O sertanejo. São Paulo: Ática, 2004.

ANDERSON, Benedict. Comunidades imaginadas. São Paulo: Companhia das Letras, 2009.

ASHCROFT, Bill et al. Post colonial studies: the key concepts. London: Routledge, 2000.

BHABHA, Homi. Narrating the nation. In: BHABHA, H. (Ed.) Nation and narration. London: Routledge, 1995.

. Of mimicry and man: the ambivalence of colonial discourse. In: MIECHELSON, Annete et al. (Eds.) October: the First Decade, 1976- 1986. Cambridge, MA: MIT Press, 1987. p. 317-325.

BONNICI, Thomas. Conceitos-chave da teoria pós-colonial. Maringá: Editora da UEM, 2005.

. Teoria e crítica pós-colonialistas. In: BONNICI, T.; ZOLIN, L. (Org.) Teoria literária: abordagens históricas e tendênias contemporâneas. Maringá: UEM, 2009.

BOSI, Alfredo. Um mito sacrificial: o indianismo de Alencar. In: BOSI, Alfredo. Dialética da colonização. São Paulo: Companhia das Letras, 2005.

CANDIDO, Antonio. Formação da literatura brasileira: momentos decisivos. Rio de Janeiro: Ouro sobre azul, 2006.

. Literatura e sociedade. São Paulo: Companhia Editora Nacional, 1967.

COMPAGNON, Antoine. O demônio da teoria: leitura e senso comum. Belo Horizonte: Editora da UFMG, 2003.

MARTINS, Eduardo Vieira. A fonte subterrânea: José de Alencar e a retórica oitocentista. Londrina/São Paulo: EDUEL/EDUSP, 2005.

A imagem do sertão em José de Alencar. Dissertação de mestrado em estudos literários. 1997, 164f. Dissertação (Mestrado em Letras) - Universidade Estadual de Campinas. Campinas: UNICAMP, 1997.

PRATT, Mary Louise. Imperial eyes: travel writing and transculturation. New York: Routledge, 1992.

SANTIAGO, Silviano. O entre-lugar do discurso latino-americano. In: . Uma literatura nos trópicos: ensaios sobre dependência cultural. São Paulo: Perspectiva, 1978.

TIFFIN, Chris; LAWSON, Alan. The textuality of empire. In: (Eds.) De-scribing empire. London: Routledge, 1994.

Recebido para publicação em 8 nov. 2010. Aceito para publicação em 1 mar. 2011. 